\title{
Effects of a Combined Inpatient-Outpatient Treatment of Obese Children and Adolescents
}

\author{
Sibylle Adam ${ }^{a, b}$ Joachim Westenhöfer ${ }^{a, b} \quad$ Birgit Rudolphi $^{c} \quad$ Hanna-Kathrin Kraaibeek $^{d}$ \\ ${ }^{a}$ Faculty Life Sciences, Hamburg University of Applied Sciences, \\ ${ }^{\mathrm{b}}$ HealthBehavior.de GmbH, Bad Schwartau, \\ ${ }^{\mathrm{C}}$ Produktmanagement/Vorsorge und Rehabilitation, \\ ${ }^{\mathrm{d}}$ Team Prävention - Gesundheitsberatung, DAK - Unternehmen Leben, Hamburg, Germany
}

\section{Key Words}

Obesity · Children · Adolescents - Therapy .

Behavior modification - Weight reduction

\section{Summary}

Background: The program ,The combined DAK therapy for obesity in children and adolescents' funded and conducted by the Deutsche Angestellten-Krankenkasse (DAK), a German health insurance company, commenced in 2003. The treatment program lasts for 1 year and comprises of 2 phases: an initial inpatient therapy for 6 weeks followed by a home-based outpatient treatment of the overweight children, adolescents, and their families for 10.5 months. The therapy complies with the guidelines of the German Working Group of Obesity in Childhood and Adolescence (AGA). Participants and Methods: In this study, 162 obese children and adolescents were compared with a control group of 75 obese subjects recruited from the waiting list for the program. The aim was to analyze whether the changes in weight, eating behavior, and physical fitness during the therapy period are a result of the therapy itself or whether they are attributable to external effects. Body weight, height, and physical fitness were assessed through direct measurements while behavior and quality of life were assessed using self-report questionnaires. The development of body weight was evaluated using the BMI-SDS which is a measure of how many standard deviations an individual BMI is above or below the age- and gender-specific mean. Results: Within the observation period the BMISDS decreased significantly by $0.36 \pm 0.34$ in the intervention group, whereas no changes of BMI-SDS were observed in the control group $(0.04 \pm 0.17)$. The study re- vealed significant, positive treatment effects in exploratory analyses with regard to weight loss, behavior changes, physical fitness, and development of quality of life as a result of the therapy. These effects were not seen in the control group. Conclusion: We conclude that these positive developments are a result of the treatment program.

\section{Introduction}

Overweight and obesity have become a major public health issue due to a steep rise in the prevalence of overweight and obesity in adults as well as adolescents and children. In Germany, the number of overweight children has more than doubled since the $80 \mathrm{~s}$ and $90 \mathrm{~s}$ - currently there are around 1.9 million overweight children and adolescents, and 800,000 are classified as obese [1].

Overweight and obesity in children and adolescents are major risk factors for many diseases, including cardiovascular diseases, diabetes, and hypertension, as well as for the psychosocial health and the musculoskeletal system [2]. Early prevention and treatment are necessary to prevent or reduce health problems and their resulting consequences [3]. According to the recommendations of experts, treatment for obesity in children and adolescents should be a combination of dietetic treatment, behavior modification, and physical exercise $[4,5]$.

According to a survey of the German Childhood Obesity Group [4], more than 4,300 children and adolescents in Germany are treated on an inpatient basis in programs with an average duration of 6 weeks, and more than 2,700 children

\section{KARGER}

Fax +497614520714

Information@Karger.de

www.karger.com (c) 2009 S. Karger GmbH, Freiburg

Accessible online at:

www.karger.com/ofa
Dipl.-Oecotroph. Sibylle Adam

Fakultät Life Sciences

Hochschule für Angewandte Wissenschaften Hamburg

Lohbrügger Kirchstraße 65, 21033 Hamburg, Germany

Tel. +49 40 42875-6121, Fax -6129

sibylle.adam@ls.haw-hamburg.de 
Table 1. Recruitment and assessment of the participants

\begin{tabular}{|c|c|c|}
\hline & CG & IG \\
\hline Number of participants registered & 133 & 190 \\
\hline Number of participants included ${ }^{\mathrm{a}}$ & 119 & 167 \\
\hline Baseline assessment & $\begin{array}{l}\text { June-August } 2004 \\
(\mathrm{n}=75)\end{array}$ & $\begin{array}{l}\text { July-November } 2004 \\
(\mathrm{n}=162)\end{array}$ \\
\hline Waiting period ${ }^{\mathrm{b}} /$ intervention period $^{\mathrm{c}}$ & 6 months & 6 months \\
\hline Follow-up assessment & $\begin{array}{l}\text { December 2004- } \\
\text { February } 2005(\mathrm{n}=71)\end{array}$ & $\begin{array}{l}\text { January-May } 2005 \\
(\mathrm{n}=138)\end{array}$ \\
\hline
\end{tabular}

$\mathrm{CG}=$ Control group; $\mathrm{IG}=$ intervention group .

${ }^{a}$ Inclusion criteria: age $\geq 10$ years and written consent.

${ }^{b}$ No intervention.

${ }^{\mathrm{C}}$ Combined inpatient-outpatient treatment. and adolescents are treated in outpatient programs with an average duration of 11 months. Usually, outpatient programs are offered close to the home of the patients whereas inpatient programs are offered in specialized hospitals often quite far from the patient's residence. Given the high prevalence of obesity, there is an obvious lack of treatment capacity in general and particularly in locally or regionally available outpatient treatment. Therefore, there is a need for remote inpatient treatment programs which can successfully assist in weight reduction [6-8]. However, evidence for long-term success and sustainability of treatment effects is still scarce [9]. It is likely that the long-term success of an inpatient treatment may be enhanced if followed by appropriate outpatient treatment programs [10].

The present study was undertaken to evaluate the effects of a combined inpatient-outpatient treatment program for obese children and adolescents in comparison to a waiting list control group (CG).

\section{Participants and Methods}

\section{Treatment Program}

The Deutsche Angestellten-Krankenkasse (DAK) is a large German health insurance company with approximately 6 million members. The program 'The combined DAK therapy for obesity in children and adolescents' was developed to provide help for member families with obese children and adolescents. The entire treatment program lasts for 1 year and includes an initial inpatient therapy of 6 weeks followed by a 10.5-monthlong outpatient treatment at the home of the obese child. To conduct the outpatient treatment, a nationwide network of nutritionists and dieticians was established. Both the children and their parents were involved in the treatment process.

The treatment program was developed in accordance with the German guidelines for the treatment of obese children [5] and based on a published treatment manual [11].

During the 6 weeks of inpatient treatment, an interdisciplinary team of pediatricians, dieticians, psychologists, exercise physiologists, and physicians are responsible for providing a structured treatment plan including both components of diet and nutritional education as well as exercise and behavioral therapy. The outpatient treatment is offered by a nutritionist or dietician from the national network and comprises 11 sessions of $1 \mathrm{~h}$ each during the 10.5-month period. The outpatient treatment includes nu- tritional education, behavioral therapy, and advice on physical activity, but does not provide a structured exercise program. The sessions were conducted according to standardized treatment protocol.

\section{Participants and Study Design}

The program 'The combined DAK therapy for obesity in children and adolescents' is designated for obese children and adolescents aged 8-15 years. In accordance with the German guidelines [5], obesity is defined as exceeding the 97 th percentile of age- and gender-specific German reference data for BMI [12]. Parents and their children have to apply on their own initiative for admission to this therapy program. In addition, for inclusion in this evaluation study, candidates had to be at least 10 years old. Younger children were not included in this study since they might experience difficulties in reading, understanding, and answering the questionnaires that were used to assess various outcome parameters. Written informed consent by the parents or guardians of the children and adolescents was required for study participation.

From May to August 2004, all eligible participants were allocated to the intervention group (IG) on a 'first come, first serve' basis by the DAK who was responsible for the organizational and financial management. Once all available treatment places were assigned, the subsequently enrolling candidates were placed on a waiting list for a period of 6 months. For this evaluation study, the candidates on the waiting list constituted the CG while the participants who started the therapy immediately represented the IG. The recruitment was completed in August 2004, and then every participant was allocated either to the IG or CG.

During the study period, a total of 323 children and adolescents applied for the participation in the therapy program. Of these, 190 were allocated to the IG and 133 to the CG. The additional study inclusion criteria (age $\geq 10$ years and written consent) led to a reduction of the sample to 119 candidates in the CG and 167 candidates in the IG (table 1). The missing baseline data for some of the participants further reduced the study sample so that finally there were 75 participants in the CG and 162 participants in the IG. Differences in the number of subjects in the tables of the results section are due to missing data in single assessment instruments.

Since the patients from the waiting list group had to wait for 6 months until they could begin with the therapy, the observation period for the present study was defined to be 6 months for both the CG and the IG.

The study design included a baseline assessment (T1) either at the start of inpatient treatment for the IG or after assignment to the waiting list for the CG. The IG then received the 6-week inpatient treatment followed subsequently by the first 4.5 months of outpatient treatment, while the $\mathrm{CG}$ received no further treatment or counseling during this time. The follow-up assessment (T2) was undertaken 6 months after the baseline assessment 
Table 2. Changes in body weight, height, BMI, and BMI-SDS

\begin{tabular}{|c|c|c|c|}
\hline & \multicolumn{2}{|c|}{ Difference baseline/follow-up } & \multirow[t]{2}{*}{ Significance } \\
\hline & $\mathrm{CG}(\mathrm{n}=75)$ & IG $(\mathrm{n}=162)$ & \\
\hline \multicolumn{4}{|l|}{ Weight, kg } \\
\hline Mean \pm SD & $3.69 \pm 3.98$ & $-4.06 \pm 5.14$ & $\mathrm{a}, \mathrm{b}, \mathrm{c}, \mathrm{e}$ \\
\hline Median (min-max) & $3.00 \pm(-5.80$ to 13.20$)$ & $-3.55(-24.70$ to 8.50$)$ & \\
\hline \multicolumn{4}{|l|}{ Body height, $m$} \\
\hline Mean \pm SD & $0.02 \pm 0.02$ & $0.02 \pm 0.02$ & $a, b, c, d$ \\
\hline Median (min-max) & $0.02(-0.02$ to 0.06$)$ & $0.02(-0.02$ to 0.12$)$ & \\
\hline \multicolumn{4}{|l|}{$B M I, \mathrm{~kg} / \mathrm{m}^{2}$} \\
\hline Mean \pm SD & $0.27 \pm 0.90$ & $-2.21 \pm 1.99$ & $\mathrm{a}, \mathrm{b}, \mathrm{c}, \mathrm{d}, \mathrm{e}$ \\
\hline Median (min-max) & $0.00(-2.09$ to 5.42$)$ & $-2.22(-8.82$ to 2.09$)$ & \\
\hline \multicolumn{4}{|l|}{$B M I-S D S$} \\
\hline Mean \pm SD & $0.04 \pm 0.17$ & $-0.36 \pm 0.34$ & $\mathrm{~b}, \mathrm{~d}, \mathrm{e}$ \\
\hline Median (min-max) & $0.02(-0.46$ to 0.47$)$ & $-0.32(-1.63$ to 0.39$)$ & \\
\hline
\end{tabular}

$\mathrm{CG}=$ Control group; $\mathrm{IG}=$ intervention group $\mathrm{SD}=$ standard deviation; min = minimum; $\max =$ maximum; $\mathrm{a}=$ difference baseline/follow-up within $\mathrm{CG}$ is significant, nominal $\mathrm{p}<0.05 ; \mathrm{b}=$ difference baseline/follow-up within IG is significant, nominal $\mathrm{p}<0.05 ; \mathrm{c}=$ difference baseline (CG) vs. baseline (IG) is significant, nominal $\mathrm{p}<0.05$; $\mathrm{d}=$ difference follow-up (CG) vs. follow-up (IG) is significant, nominal $\mathrm{p}<0.05 ; \mathrm{e}=$ difference baseline/follow-up is significantly different between CG and IG, nominal $\mathrm{p}<0.05$.
The data from the CG was collected by local dieticians at the home of the patients. For the IG, the baseline data collection took place at the start of inpatient treatment in the DAK hospital in Westerland, Sylt, Germany, while the follow-up data was collected at the home of the patients by the local dietician. Data collection took place from June 2004 to March 2005. The parallel data collection from both the CG and the IG enabled us to avoid differences that could be due to seasonal variations (e.g. holidays, Christmas season etc.).

\section{Instruments and Measures}

Body weight and height were measured directly while behavioral characteristics, nutritional habits, and exercise status as well as quality of life were assessed by questionnaires. All the questionnaires used have been published previously [11].

\section{Body Weight Development}

Body weight was evaluated using age- and sex-specific standard deviation scores of the BMI-SDS. BMI was calculated from measured weight and height $\left(\mathrm{kg} / \mathrm{m}^{2}\right)$ and then converted to BMI-SDS using German reference data [12] and the formulas provided for these data which are based on the LMS transformation of BMI [13]. BMI-SDS indicates how many standard deviations an individual BMI is above or below the mean of the corresponding population and is considered to be an adequate measure for assessing change over time $[12,14]$. A successful weight reduction for adults corresponds to a weight reduction of at least $5 \%$ after 1 year with respect to the initial weight [15]. Applying these criteria to children would mean that a weight reduction of at least $0.2 \mathrm{BMI-SDS}$ is a successful weight reduction [16]. Therefore, for this study a reduction in BMISDS of 0.2 or more was considered as a positive outcome, i.e. a successful weight reduction.

\section{Eating Behavior}

The eating behavior was evaluated using the eating behavior questionnaire for children, which is an adapted and abridged version of the German version of the 'Three-Factor Eating Questionnaire' (TFEQ) [17, 18]. This questionnaire provides scores for the 2 scales cognitive control/
Table 3. Categories of weight reduction

\begin{tabular}{lcl}
\hline & CG, \% & IG, \% \\
\hline No weight reduction & 58.7 & 14.2 \\
Reduced weight $<0.2$ BMI-SDS & 37.3 & 20.4 \\
Reduced weight $\geq 0.2$ to $<0.5$ BMI-SDS & 4.0 & 38.3 \\
Reduced weight $\geq 0.5$ BMI-SDS & 0.0 & 27.2 \\
\hline
\end{tabular}

$\mathrm{CG}=$ Control group; $\mathrm{IG}=$ intervention group.

Table 4. Changes in eating behavior from baseline to follow-up

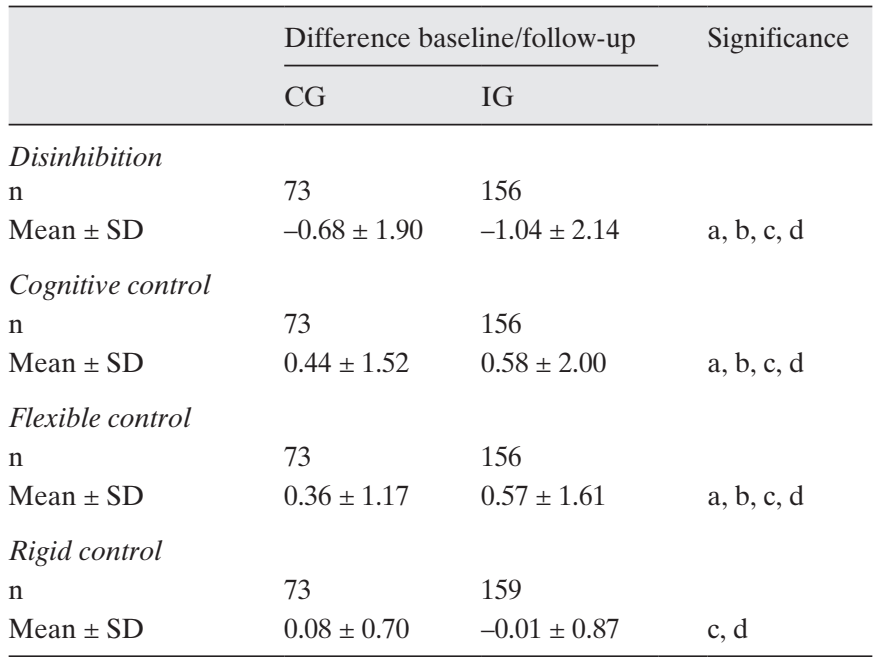

$\mathrm{CG}=$ Control group; $\mathrm{IG}=$ intervention group; $\mathrm{SD}=$ standard deviation; $\min =$ minimum $; \max =$ maximum $; \mathrm{a}=$ difference baseline/follow-up within $C G$ is significant, nominal $\mathrm{p}<0.05 ; \mathrm{b}=$ difference baseline/followup within IG is significant, nominal $\mathrm{p}<0.05 ; \mathrm{c}=$ difference baseline $(\mathrm{CG})$ vs. baseline (IG) is significant, nominal $\mathrm{p}<0.05 ; \mathrm{d}=$ difference follow-up (CG) vs. follow-up (IG) is significant, nominal p $<0.05$. 
Table 5. Changes in food intake from baseline to follow-up assessment (average number or portions per week $\pm \mathrm{SD}$ )

\begin{tabular}{|c|c|c|c|c|}
\hline & \multirow[t]{2}{*}{ Group } & \multicolumn{2}{|c|}{$\begin{array}{l}\text { Difference baseline/ } \\
\text { follow-up }\end{array}$} & \multirow[t]{2}{*}{ Significance } \\
\hline & & $\mathrm{n}$ & mean $\pm \mathrm{SD}$ & \\
\hline \multirow[t]{2}{*}{ Whole grain products } & CG & 72 & $0.40 \pm 9.76$ & \multirow[t]{2}{*}{$\mathrm{b}, \mathrm{c}, \mathrm{d}$} \\
\hline & IG & 157 & $2.94 \pm 13.36$ & \\
\hline \multirow[t]{2}{*}{ Superfine lour grain products } & CG & 71 & $-2.00 \pm 10.17$ & \multirow[t]{4}{*}{$b, d$} \\
\hline & IG & 157 & $-3.69 \pm 11.69$ & \\
\hline \multirow[t]{2}{*}{ Potatoes in their skin, boiled potatoes } & CG & 73 & $0.38 \pm 5.66$ & \\
\hline & IG & 160 & $-0.07 \pm 6.11$ & \\
\hline \multirow[t]{2}{*}{ French fries, fried potatoes } & CG & 72 & $0.11 \pm 2.00$ & \multirow[t]{2}{*}{$\mathrm{b}$} \\
\hline & IG & 156 & $-1.01 \pm 4.49$ & \\
\hline \multirow[t]{2}{*}{ Vegetables, salad, frozen vegetables } & CG & 73 & $-0.19 \pm 14.33$ & \multirow[t]{4}{*}{ d } \\
\hline & IG & 161 & $-0.50 \pm 13.59$ & \\
\hline \multirow[t]{2}{*}{ Vegetables in glasses or cans } & CG & 73 & $0.15 \pm 5.89$ & \\
\hline & IG & 161 & $-1.17 \pm 6.12$ & \\
\hline \multirow[t]{2}{*}{ Fresh fruits } & $\mathrm{CG}$ & 72 & $-0.92 \pm 10.11$ & \multirow[t]{2}{*}{$\mathrm{c}, \mathrm{d}$} \\
\hline & IG & 159 & $0.81 \pm 10.28$ & \\
\hline \multirow[t]{2}{*}{ Fruits in cans } & CG & 73 & $-0.07 \pm 3.78$ & \multirow[t]{2}{*}{$\mathrm{b}, \mathrm{c}, \mathrm{d}$} \\
\hline & IG & 159 & $-1.00 \pm 5.18$ & \\
\hline \multirow[t]{2}{*}{ Milk and milk products } & CG & 70 & $1.57 \pm 16.60$ & \multirow[t]{2}{*}{$\mathrm{c}, \mathrm{b}, \mathrm{e}$} \\
\hline & IG & 151 & $-7.49 \pm 20.98$ & \\
\hline \multirow[t]{2}{*}{ Meat, sausages, sea food, eggs } & CG & 71 & $-0.10 \pm 13.90$ & \multirow[t]{2}{*}{$\mathrm{c}, \mathrm{b}, \mathrm{e}$} \\
\hline & IG & 159 & $-7.76 \pm 21.00$ & \\
\hline \multirow[t]{2}{*}{ Butter and margarine } & $\mathrm{CG}$ & 71 & $-0.08 \pm 11.60$ & \multirow[t]{2}{*}{$\mathrm{b}, \mathrm{e}$} \\
\hline & IG & 157 & $-4.31 \pm 13.20$ & \\
\hline \multirow[t]{2}{*}{ Mineral water, fruit tea, herb tea } & $\mathrm{CG}$ & 73 & $-0.48 \pm 12.82$ & \multirow[t]{2}{*}{$b, d$} \\
\hline & IG & 158 & $3.86 \pm 11.07$ & \\
\hline \multirow[t]{2}{*}{ Coffee, black tea } & $\mathrm{CG}$ & 73 & $0.86 \pm 4.30$ & \multirow[t]{2}{*}{ c } \\
\hline & IG & 160 & $-0.64 \pm 5.52$ & \\
\hline \multirow{3}{*}{$\begin{array}{l}\text { High-calorie beverages } \\
\text { (e.g. lemonade, juice) }\end{array}$} & & & & \multirow{3}{*}{$\mathrm{b}$} \\
\hline & $\mathrm{CG}$ & 72 & $-2.25 \pm 16.74$ & \\
\hline & IG & 156 & $-4.49 \pm 18.56$ & \\
\hline Sweets & CG & 71 & $-7.23 \pm 22.26$ & $a, b$ \\
\hline & IG & 147 & $-12.01 \pm 25.33$ & \\
\hline Fast food & CG & 72 & $-0.18 \pm 2.77$ & $\mathrm{~b}, \mathrm{~d}, \mathrm{e}$ \\
\hline & IG & 153 & $-1.03 \pm 3.51$ & \\
\hline
\end{tabular}

$\mathrm{CG}=$ Control group $; \mathrm{IG}=$ intervention group; $\mathrm{SD}=$ standard deviation $; \min =$ minimum; $\max =$ maximum; $\mathrm{a}=$ difference baseline/follow-up within $\mathrm{CG}$ is significant, nominal $\mathrm{p}<0.05 ; \mathrm{b}=$ difference baseline/follow-up within IG is significant, nominal $\mathrm{p}<0.05 ; \mathrm{c}=$ difference baseline $(\mathrm{CG})$ vs. baseline (IG) is significant, nominal $\mathrm{p}<0.05 ; \mathrm{d}=$ difference follow-up (CG) vs. follow-up (IG) is significant, nominal $\mathrm{p}<0.05 ; \mathrm{e}=$ difference baseline/follow-up is significantly different between CG and IG, nominal $\mathrm{p}<0.05$. restrained eating and disinhibition. Cognitive control/restrained eating measures the tendency to deliberately restrict food intake in order to lose weight or prevent weight gain, while disinhibition measures the tendency to increase food intake and overeat when exposed to emotional distress or to tempting external stimuli. In addition, 2 subscales of cognitive control are provided: rigid control of eating behavior and flexible control of eating behavior [19]. In adults, flexible control is associated with better long-term weight loss and a lower tendency to overeat, whereas rigid control is associated with weight gain and an increased tendency to overeat.

\section{Food Intake}

A food frequency list was used to assess the food intake of the children. For each of the food items and food groups listed, the participants had to indicate how many portions they usually eat, using 5 answer options: i) 3-5 portions per day, ii) 1-2 portions per day, iii) 4-6 portions per week, iv) 1-3 portions per week, or v) never. These answer categories were converted to the number of portions per week for further analysis.

The reliability of the food frequency list was assessed by computing test-retest reliabilities from the data of the untreated waiting list control groups. The test-retest correlations ranged from 0.31 to 0.73 and were highly significant $(\mathrm{p}<0.01)$, with the exception of 'vegetable items'. 
Table 6. Changes in the walking test results from baseline to follow-up

\begin{tabular}{|c|c|c|c|}
\hline & \multicolumn{2}{|c|}{ Difference baseline/follow-up } & \multirow[t]{2}{*}{ Significance } \\
\hline & CG & IG & \\
\hline \multicolumn{4}{|c|}{ Heart rate in rest, beats/min } \\
\hline $\mathrm{n}$ & 26 & 161 & \\
\hline Mean \pm SD & $-1 \pm 11.89$ & $-4 \pm 14.89$ & $\mathrm{~b}$ \\
\hline Median (min-max) & $0(-25$ to 28$)$ & $0(-50$ to 45$)$ & \\
\hline \multicolumn{4}{|l|}{ Walking distance, $m$} \\
\hline $\mathrm{n}$ & 26 & 161 & \\
\hline Mean \pm SD & $6 \pm 76.18$ & $20 \pm 120.88$ & $\mathrm{c}, \mathrm{d}$ \\
\hline Median (min-max) & $6(-200$ to 170$)$ & $20(-331$ to 809$)$ & \\
\hline \multicolumn{4}{|c|}{ Heart rate 2 min after ending test } \\
\hline $\mathrm{n}$ & 24 & 161 & \\
\hline Mean \pm SD & $-4 \pm 11.76$ & $-15 \pm 22.51$ & $\mathrm{~b}, \mathrm{c}, \mathrm{d}, \mathrm{e}$ \\
\hline Median (min-max) & 0 (-20 to 33$)$ & $-3(-69$ to 95$)$ & \\
\hline \multicolumn{4}{|c|}{ Heart rate 10 min after ending test } \\
\hline $\mathrm{n}$ & 24 & 161 & \\
\hline Mean \pm SD & $-5 \pm 13.65$ & $-9 \pm 16.60$ & $\mathrm{~b}, \mathrm{c}, \mathrm{e}$ \\
\hline Median (min-max) & $0(-22$ to 36$)$ & $0(-64$ to 27$)$ & \\
\hline \multicolumn{4}{|c|}{ Reduction of heart rate, beats/min* } \\
\hline $\mathrm{n}$ & 23 & 161 & \\
\hline Mean \pm SD & $0 \pm 12.00$ & $-27 \pm 8.75$ & $\mathrm{~b}, \mathrm{c}, \mathrm{d}, \mathrm{e}$ \\
\hline Median (min-max) & $0(-28$ to 24$)$ & $-5(-52$ to 95$)$ & \\
\hline
\end{tabular}

$\mathrm{CG}=$ Control group; $\mathrm{IG}=$ intervention group; $\mathrm{SD}=$ standard deviation; $\min =$ minimum; $\max =$ maximum; $\mathrm{a}=$ difference baseline/follow-up within $\mathrm{CG}$ is significant, nominal $\mathrm{p}<0.05 ; \mathrm{b}=$ difference baseline/follow-up within IG is significant, nominal $\mathrm{p}<0.05 ; \mathrm{c}=$ difference baseline (CG) vs. baseline (IG) is significant, nominal $\mathrm{p}<0.05$; $\mathrm{d}=$ difference follow-up (CG) vs. follow-up (IG) is significant, nominal $\mathrm{p}<0.05 ; \mathrm{e}=$ difference baseline/follow-up is significantly different between $\mathrm{CG}$ and IG, nominal $\mathrm{p}<0.05$.

*Calculation method: heart rate 10 min after ending test - heart rate 2 min after ending test.
Physical Activity and Fitness Status

Physical activity and time spent watching TV or engaging in PC activities was assessed using a questionnaire.

A 6-min walking test was employed to measure the fitness status of the participants. The test allows for an estimation of the dynamic endurance capacity [11]. Usually, the test is conducted on a treadmill, but it was also possible to complete the test on a sports field where a defined track of $400 \mathrm{~m}$ is available. The children were asked to walk briskly, yet every child could determine its own walking speed. At the end of the $6 \mathrm{~min}$, the distance covered was measured. In addition, the pulse rate was measured both at rest, i.e. before the walking exercise, and after walking.

\section{Self-Perception and Quality of Life}

A questionnaire was used to assess the children's perceived self-competence. This questionnaire measures scores for 5 characteristics: attractiveness, self-confidence, competence at school, self-esteem, and social acceptance [20]. For assessing the quality of life, a questionnaire developed by Warschburger [21,22] was used.

\section{Statistical Analysis}

The statistical analysis was done by an intention to treat analysis where the missing data for follow-up measurement are imputed using the baseline values (return to baseline or baseline observation carried forward). Results are presented as mean \pm standard deviation. Because of a missing normal distribution and different sample sizes of the CG and IG, the me- dian and sometimes the maximum and minimum are given as well. Both the changes identified during the 6-month observation period as well as the differences in data between the IG and CG were analyzed. For testing the statistical significance, we used the Wilcoxon test for independent samples and the Mann-Whitney U-test for dependent samples; the significance level was set to $\mathrm{p}<0.05$, two-tailed. The primary hypothesis for this study was that the IG would achieve a better reduction of BMI-SDS. All other tests are considered to be exploratory analyses.

\section{Results}

The distribution of girls and boys among the IG and CG was similar with $58.0 \%$ girls and $42.0 \%$ boys in each group. The age distribution was also quite similar in both groups. At the beginning of the study, the average age of the children in the IG was $12.5 \pm 1.35$ years, and in the CG the children were 11.9 \pm 1.19 years old

\section{Body Weight Development}

Within the 6-month observation period the BMI-SDS decreased significantly by $0.36 \pm 0.34$ in the IG (table 2 ). Nearly no difference (from the baseline) in BMI-SDS was observed 
in the CG $(0.04 \pm 0.17)$. In addition, the calculated difference 'baseline/follow-up' was significantly different between the $\mathrm{CG}$ and the $\mathrm{IG}$.

Overall, $65.5 \%$ of children in the IG successfully reduced their body weight, as indicated by a decrease of BMI-SDS of 0.2 or more. At the same time, only a small minority of children in the CG was successful in reducing their body weight (table 3).

\section{Eating Behavior}

Both groups showed changes in eating behavior (table 4). Both cognitive control/restrained eating and flexible control eating behavior increased whereas disinhibition of control decreased. The changes were slightly more pronounced in the IG; however, the magnitude of the changes did not differ significantly between the groups.

\section{Food Intake}

In the CG, only the intake of sweets changed significantly during the observation period. In contrast, the IG showed significant changes in food intake for a number of food groups (table 5). Overall, the changes in food intake were significantly different between CG and IG for whole grain, milk and milk products, spread, meat, sausages, sea food and eggs, and fast food.

\section{Physical Activity and Fitness Status}

No significant differences were observed between the CG and IG concerning the self-reported activities indulged in when together with friends during leisure time, nor in the time spent watching TV or using the PC.

Also, the question on how often the participants indulged in physical activity for at least 20 min per week showed no significant difference between baseline and follow-up measurements both within the CG and the IG (CG: baseline 8.29 \pm 5.40 vs. follow-up $7.30 \pm 5.88$; IG: baseline $11.17 \pm 7.33$ vs. follow-up $10.67 \pm 7.77$ ).

However, in the IG there was an increase in the numbers of subjects reporting regular physical exercise by $8.8 \%$ at follow-up, whereas in the CG there was no increase.

In contrast, significant differences were measured for the 6-min walking test, i.e. fitness status. In the CG, neither the walking distance nor the heart rate changed significantly between baseline and follow-up. In contrast, walking distance increased significantly in the IG, while the heart rate after the walking exercise was at the same time significantly lower at follow-up as compared to baseline, indicating a better physical fitness (table 6).

\section{Self-Perception and Quality of Life}

All assessed aspects of self-perception improved significantly in the IG. For attractiveness, self-confidence, and self-esteem, the improvements were significantly higher in the IG compared to the CG (table 7).
Table 7. Changes of self-perception between baseline and follow-up

\begin{tabular}{|c|c|c|c|}
\hline & \multicolumn{2}{|c|}{ Difference baseline/follow-up } & \multirow[t]{2}{*}{ Significance } \\
\hline & $\mathrm{CG}$ & IG & \\
\hline \multicolumn{4}{|c|}{ Attractiveness } \\
\hline $\mathrm{n}$ & 69 & 157 & \\
\hline Mean \pm SD & $0.06 \pm 0.38$ & $0.48 \pm 0.64$ & $\mathrm{a}, \mathrm{b}, \mathrm{c}, \mathrm{d}, \mathrm{e}$ \\
\hline \multicolumn{4}{|c|}{ Competence at school } \\
\hline $\mathrm{n}$ & 69 & 157 & \\
\hline Mean \pm SD & $0.12 \pm 0.58$ & $0.17 \pm 0.53$ & $\mathrm{~b}, \mathrm{c}, \mathrm{d}$ \\
\hline \multicolumn{4}{|c|}{ Self-confidence } \\
\hline $\mathrm{n}$ & 70 & 157 & \\
\hline Mean \pm SD & $0.00 \pm 0.56$ & $0.23 \pm 0.50$ & $\mathrm{~b}, \mathrm{~d}, \mathrm{e}$ \\
\hline \multicolumn{4}{|l|}{ Self-esteem } \\
\hline $\mathrm{n}$ & 69 & 157 & \\
\hline Mean \pm SD & $0.09 \pm 0.56$ & $0.30 \pm 0.63$ & $\mathrm{~b}, \mathrm{~d}, \mathrm{e}$ \\
\hline \multicolumn{4}{|c|}{ Social acceptance } \\
\hline $\mathrm{n}$ & 69 & 157 & \\
\hline Mean \pm SD & $-0.06 \pm 0.57$ & $0.16 \pm 0.46$ & $\mathrm{a}, \mathrm{b}, \mathrm{d}$ \\
\hline
\end{tabular}

$\mathrm{CG}=$ Control group; $\mathrm{IG}=$ intervention group; $\mathrm{SD}=$ standard deviation; $\min =$ minimum $; \max =$ maximum $; \mathrm{a}=$ difference baseline $/$ follow-up within CG is significant, nominal $\mathrm{p}<0.05 ; \mathrm{b}=$ difference baseline/followup within IG is significant, nominal $\mathrm{p}<0.05 ; \mathrm{c}=$ difference baseline $(\mathrm{CG})$ vs. baseline (IG) is significant, nominal $\mathrm{p}<0.05$; $\mathrm{d}=$ difference follow-up (CG) vs. follow-up (IG) is significant, nominal $\mathrm{p}<0.05$; e = difference baseline/follow-up is significantly different between $\mathrm{CG}$ and IG, nominal $\mathrm{p}<0.05$.

Also, perceived quality of life improved significantly in the IG (T1: $3.16 \pm 0.69 ; \mathrm{T} 2: 3.67 \pm 0.68)$. In the $\mathrm{CG}$, a slight but still significant increase in quality of life could be observed as well (T1: $2.98 \pm 0.71 ; \mathrm{T} 2: 3.18 \pm 0.80)$, but the increase in the IG $(+0.50 \pm 0.76)$ was significantly higher than in the CG $(+0.15 \pm 0.65)$.

\section{Discussion}

The aim of this study was to evaluate the effectiveness of a combined inpatient-outpatient treatment for obese children and adolescents that is being offered by the DAK. The combination of inpatient and outpatient treatment in the therapy of childhood and adolescence obesity is an often discussed issue but nevertheless a new approach in Germany. We used a waiting list CG to compare the effect of treatment to nontreatment over a period of 6 months. To our knowledge, this is the first study which assesses the effects of a combined inpatient-outpatient approach using a CG design. However, using this design, a number of limitations have to be acknowledged.

First of all, due to legal concerns regarding the access to standard treatment offered by a health insurance company, we were not able to randomize the allocation to the IG and CG. Thus, bias resulting from allocation to intervention or 
waiting list group can not be totally excluded. Group assignment was based on the sequence of applications for treatment. Thus, it might be suspected that bias could result from motivational differences. However, this is unlikely because patients in the IG were those subjects who were the first to apply for treatment after May 2004. Since the treatment program itself started in January 2004 and numerous enrolments had taken place before May 2004, the risk that the first 190 applicants after May differ systematically from the next 133 may be considered minimal. In addition, the IG and CG did not differ with regard to age, sex distribution, and baseline BMI-SDS. Since both baseline and follow-up assessment took place at the same time periods in both groups, any seasonal bias can be excluded.

However, an important limitation regarding the CG is a considerable dropout. From the 119 CG subjects who provided informed consent, we could not obtain baseline data for 44 subjects, leaving only 75 patients in the CG for the final analysis. This selection may have yielded some bias which has to be taken into account. Nevertheless, since those patients who remained in the CG might be assumed to have higher motivation than those who dropped out, we would expect that the resulting bias is towards better weight and behavior change within the CG. Hence, differences between the CG and the IG would become more difficult to detect. Since we found a significant difference between the IG and CG, we concluded that this potential limitation did not impair our results too much. Another limitation results from the fact that the observation period for the present study was limited to 6 months due to ethical considerations, whereas the combined inpatient-outpatient treatment has a duration of 12 months. Thus, only half of the time period of this program could be evaluated in this study. Nevertheless, we consider the study design sufficiently valid to yield meaningful conclusions about the effectiveness of the studied treatment approach.

A further limitation that should be noted is that a number of the investigated parameters, in particular regarding eating behavior, food intake, self-perception, and quality of life, rely on self-reports and therefore self-perception of the subjects. Such self-reports and self-perceptions may be unreliable and biased. Therefore, objective measurements of body weight are crucial to ascertain that the treatment affected not only self-perception but also real behavior, which is eventually reflected in the physical state.

In addition, we analyzed a relatively large number of behavioral and psychosocial variables in an exploratory analysis without adjusting significance levels for multiple testing. This increases, of course, the probability of inflating the number of significant results. However, this may be justified since the change in BMI-SDS was the primary analysis of interest, and all other analyses have only exploratory character to shed some light on the associated behavioral and psychosocial changes.
The present study found some subtle changes in eating behavior and food intake in the CG during the study period. These changes may result from developmental processes in the subjects and from seasonal variations in food choice, and they may also be a result of the participants from the waiting list knowing that they would begin with a treatment program for their obesity within the next months. Such influencing factors underline the necessity to compare treatment effects to a $\mathrm{CG}$ in order to ascertain that the treatment has additional and superior effects.

Considering the weight reduction as an important outcome parameter, we observed a significantly higher BMI-SDS reduction within the IG as compared to the CG. More than half of the subjects in the IG were successful in reducing their weight by more than 0.2 BMI-SDS units. Since the difference was greater than 0.2 , this decrease can be interpreted as a successful weight reduction within the IG [16].

In addition, a number of other significant improvements were observed. These included a generally healthier food intake, improvement in the subjective of quality of life as well as several aspects of self-perception, and a better physical fitness was found. These factors clearly demonstrate the effectiveness of the combined treatment approach over a period of 6 months.

A follow-up period of 6 months is rather short, given the fact that long-term maintenance of improved weight and health behavior is the actual goal. An uncontrolled observational study of participants in this program over 12 months [23] showed that most of the major improvements resulted from the inpatient phase of the treatment. During the outpatient phase, primarily a maintenance of the effects over the 12-month treatment period is achieved. In addition, we are currently making efforts to extend the observation period to 5 years after the start of initial treatment in order to ascertain the long-term effects of this approach.

The overall conclusion drawn from our evaluation is that an intensive inpatient treatment phase followed by a prolonged outpatient treatment at the homes of the patients is a promising and successful format and a feasible approach for the treatment of obese children and adolescents.

\section{Acknowledgements}

This study was funded by the Deutsche Angestellten-Krankenkasse (DAK).

\section{Disclosure}

BR and HK are employed by the Deutsche Angestellten-Krankenkasse (DAK). 


\section{References}

1 Kurth BM, Schaffrath Rosario A: Die Verbreitung von Übergewicht und Adipositas bei Kindern und Jugendlichen in Deutschland. Bundesgesundheitsbl Gesundheitsforsch Gesundheitsschutz 2007;50:736743.

$\checkmark 2$ Harrell JS, Jessup A, Greene N: Changing our future: obesity and the metabolic syndrome in children and adolescents. J Cardiovasc Nurs 2006;21: 322-330.

3 Müller MJ, Reinehr T, Hebebrand J: Prävention und Therapie von Übergewicht im Kindes- und Jugendalter. Dtsch Arztebl 2006;103:A334-340.

4 Reinehr T, Wabitsch M: Strukturierte Erfassung der Therapieangebote für adipöse Kinder und Jugendliche. Ein Projekt der Arbeitsgemeinschaft Adipositas im Kindes- und Jugendalter. Monatsschr Kinderheilkd 2003;151:757-761.

5 Arbeitsgemeinschaft Adipositas im Kindes- und Jugendalter der Deutschen Adipositas-Gesellschaft: Leitlinien. www.a-g-a.de/Leitlinie.pdf.

6 Wabitsch M, Braun U, Heinze E, Muche R, Mayer $\mathrm{H}$, Teller W, Fusch C: Body composition in 5-18-yold obese children and adolescents before and after weight reduction as assessed by deuterium dilution and bioelectrical impedance analysis. Am J Clin Nutr 1996;64:1-6.

7 Zwiauer K: Therapie der Adipositas im Kindesund Jugendalter. Wien Med Wochenschr 1998;148: 403-406.

$>8$ Kiess W, Reich A, Müller G, Galler A, Kapellen T, Raile K, Böttner A, Seidel B, Kratzsch J: Obesity in childhood and adolescence: clinical diagnosis and management. J Pediatr Endocrinol Metab 2001; 14(suppl 6):1431-1440.

$\checkmark 9$ Reinehr T, Wabitsch M: Treatment of obese children and adolescents in Germany. J Pediatr Gastroenterol Nutr 2003;37:208.
10 van Egmond-Fröhlich A, Bräuer W, Goldschmidt $\mathrm{H}$, Hoff-Emden H, Oepen J, Zimmermann E: Effekte eines strukturierten ambulanten Weiterbehandlungsprogramms nach stationärer medizinischer Rehabilitation bei Kindern und Jugendlichen mit Adipositas - Multizentrische, randomisierte, kontrollierte Studie. Rehabilitation (Stuttg) 2006;45:40-51.

11 aid Infodienst, Deutsche Gesellschaft für Ernährung (eds): Trainermanual Leichter, aktiver, gesünder. Interdisziplinäres Konzept für die Schulung übergewichtiger Kinder und Jugendlicher. Bonn, aid Infodienst, 2004.

12 Kromeyer-Hauschild K, Wabitsch M, Kunze D, Geller F, Ziegler A, Geiß HC, Hesse V, von Hippel A, Jäger U, Johnsen D, Kiess W, Korte W, Menner K, Müller M, Niemann-Pilatus A, Remer T, Schäfer F, Wittchen HU, Zabransky S, Zellenr K, Hebebrand J: Perzentile für den Body Mass Index für das Kindes- und Jugendalter unter Heranziehung verschiedener deutscher Stichproben. Monatsschr Kinderheilkd 2001;149:807-818.

13 Cole TJ: The LMS method for constructing normalized growth standards. Eur J Clin Nutr 1990;44:4560.

14 Wabitsch M, Zwieauer K, Hebebrand J, Kiess W (eds): Adipositas bei Kindern und Jugendlichen. Berlin, Springer, 2005.

15 Deutsche Adipositas-Gesellschaft, Deutsche Diabetes-Gesellschaft, Deutsche Gesellschaft für Ernährung, Deutsche Gesellschaft für Ernährungsmedizin (eds): Evidenzbasierte Leitlinie zur Prävention und Therapie der Adipositas. Version 2007. www.adipositas-gesellschaft.de/daten/Adipositas-Leitlinie-2007.pdf.
16 Böhler T, Wabitsch M, Winkler U: Konsensuspapier Patientenschulungsprogramme für Kinder und Jugendliche mit Adipositas; in Bundeszentrale für gesundheitliche Aufklärung (BZGA) (ed): Gesundheitsförderung konkret, Band 4. Köln, BZGA, 2005, pp 37-55.

17 Pudel V, Westenhöfer J: Fragebogen zum Essverhalten. Handanweisung. Göttingen, Hogrefe, 1989.

18 Stunkard AJ, Messick S: The three-factor eating questionnaire to measure dietary restraint, disinhibition and hunger. J Psychosom Res 1985;29:71-83.

19 Westenhoefer J, Stunkard AJ, Pudel V: Validation of the flexible and rigid control dimensions of dietary restraint. Int J Eat Disord 1999;26:53-64.

20 Wünsche P, Schneewind KA: Entwicklung eines Fragebogens zur Erfassung von Selbst- und Kompetenzeinschätzung bei Kindern (FSK-K). Diagnostica 1989;35:217-235.

21 Warschburger P, Fromme C, Petermann F: Gewichtsbezogene Lebensqualität bei Schulkindern Validität des GW-LQ-KJ. Z Gesundheitspsych 2004; 12:159-166.

22 Warschburger P: Konzeption und Analyse eines gewichtsspezifischen Lebensqualitätsfragebogens für übergewichtige Kinder und Jugendliche (GWLQ-KJ). Z Klin Psychol Psychiatr Psychother 2005; 53:356-369.

23 Adam S, Westenhöfer J, Rudolphi B, Kraaibeek HK: Kombinierte stationäre und ambulante Adipositasbehandlung für Kinder und Jugendliche. Evaluation nach einem Jahr. MMW Fortschr Med 2008; 150(Originalien 1):7-15. 